\title{
PEMAHAMAN HAKIKAT SAINS DAN INKUIRI ILMIAH CALON GURU KIMIA
}

\author{
Iffatul Muna ${ }^{a}$, Sri Rahayu ${ }^{b}$, Siti Marfu'ah ${ }^{c}$ \\ a,b,cJurusan Kimia FMIPA Universitas Negeri Malang
}

\begin{abstract}
Abstrak - Mewujudkan masyarakat berliterasi sains adalah salah satu tujuan utama pendidikan sains, termasuk kimia. Pemahaman hakikat sains merupakan salah satu ciri yang diinginkan pada seseorang yang berliterasi sains. Pemahaman hakikat sains siswa sangat bergantung pada pemahaman hakikat sains guru. Guru harus memiliki pemahaman hakikat sains yang baik sekaligus cara membelajarkannya kepada siswa. Hakikat sains dapat dibelajarkan melalui pembelajaran berbasis inkuiri ilmiah. Calon guru kimia juga harus memiliki pemahaman hakikat sains dan inkuiri ilmiah yang baik agar mampu menjadi guru kimia yang dapat membelajarkan hakikat sains melalui pembelajaran berbasis inkuiri ilmiah, yang pada akhirnya dapat meningkatkan literasi sains siswa.
\end{abstract}

Kata kunci: hakikat sains, inkuiri ilmiah, calon guru kimia

\begin{abstract}
Educating people to be a scientifically literate is one of the main goals of science education, including chemistry. Understanding of the nature of science (NOS) is one of the desirable characteristics of a scientifically literate person. Student's understanding of the NOS depends strongly upon the teacher's understanding of the NOS. Teachers must possess adequate understanding of the NOS as well as how they can be taught to students. The NOS can be learned through scientific inquiry-based learning. Preservice chemistry teachers' also must possess adequate understanding of the NOS and scientific inquiry in order to become a chemistry teacher that can teach the NOS through scientific inquiry-based learning, which in turn can improve student's science literacy.
\end{abstract}

Keywords: nature of science, scientific inquiry, preservice chemistry teacher

\section{PENDAHULUAN}

Seiring kemajuan ilmu pengetahuan dan teknologi dan berbagai dampak serta masalah yang ditimbulkannya, semakin diperlukan hadirnya masyarakat yang memiliki literasi sains. Literasi sains semakin diperlukan ditengah-tengah kehidupan masyarakat modern saat ini, oleh karena itu mewujudkan masyarakat yang memiliki literasi sains menjadi salah satu tujuan utama pendidikan sains (Norris \& Philips, 2003). Pengembangan pemahaman hakikat sains adalah salah satu tujuan pembelajaran sains yang diyakini dapat mengembangkan kemampuan literasi sains siswa (Liang, dkk., 2009). Hasil penelitian menunjukkan bahwa pemahaman hakikat sains diperlukan siswa dalam membuat keputusan yang tepat dan bertindak secara bertanggung jawab sebagai bagian 
dari masyarakat ketika dihadapkan dengan isu-isu kompleks terkait sains (Allchin, 2011; Khisfe 2012). Pemahaman hakikat sains merupakan ciri yang diharapkan ada pada seseorang yang memiliki literasi sains (Hurd, 1998). Pemahaman hakikat sains siswa sangat bergantung pada pemahaman hakikat sains guru sains, termasuk guru kimia di sekolah. Selain pemahaman hakikat sains yang baik, guru kimia juga perlu memahami cara membelajarkan hakikat sains kepada siswa (Schwartz, dkk., 2004). Dalam makalah ini akan dipaparkan tentang: (a) pentingnya literasi sains, (b) hakikat sains sebagai komponen penting literasi sains, dan (c) peran pembelajaran berbasis inkuiri ilmiah dalam membelajarkan hakikat sains.

\section{PEMBAHASAN}

\section{Pentingnya Literasi Sains}

Literasi sains umumnya didefinisikan sebagai pengembangan pemahaman yang mendalam tentang konsep-konsep ilmiah utama, proses penyelidikan ilmiah dan hakikat sains (nature of science), serta pengembangan kemampuan untuk membuat keputusan yang tepat berdasarkan ilmu pengetahuan dan teknologi yang berkaitan dengan masalah-masalah pribadi dan sosial (Bell, 2007, Crawford \& Lederman, 2003). Oleh karena itu, banyak ahli pendidikan melihat bahwa literasi sains merupakan solusi pendidikan untuk tantangan ekonomi, sosial dan lingkungan dari abad berikutnya. Bahkan, Holbrook dan Rannikmae (2009) menyatakan bahwa literasi sains merupakan tujuan pendidikan sains.

Gräber dalam Holbrook dan Rannikmae (2009) mengajukan model literasi, menurutnya literasi sains tediri dari berbagai macam kompetensi. Kelompok kompetensi pertama yaitu what do people know, yaitu kompetensi konten sains dan kompetensi epistemologis. Kelompok kompetensi kedua yaitu what do people value, mengenai kompetensi etika/moral, dan kelompok kompetensi ketiga yaitu what can people do meliputi kompetensi belajar, sosial, prosedural dan komunikasi. Model ini menekankan perlunya keseimbangan antara berbagai kompetensi literasi sains. Literasi sains dipandang tidak hanya sebagai komponen penting pendidikan sains, tetapi meski hanya disebutkan sekilas sebagai kompetensi etika/moral, namun kompetensi ini juga berhubungan dengan hak asasi manusia, toleransi, pendidikan untuk perdamaian, persamaan gender, dan lain-lain. Pendidikan sains memainkan peran penting dalam mengembangkan warga negara yang bertanggung jawab, dalam hal ini literasi sains diperlukan dalam pengambilan keputusan sosial-saintifik.

\section{Hakikat Sains Sebagai Komponen Penting Literasi Sains}

Istilah hakikat sains atau biasa disebut nature of science (NOS) mengacu pada epistemologi sains, sains sebagai cara untuk mengetahui, atau nilai dan keyakinan yang melekat pada perkembangan sains (Lederman, 1992). Hakikat sains memiliki beberapa aspek fundamental. Aspek hakikat sains yang paling relevan untuk siswa sekolah menengah diantaranya: (1) sains dikembangkan berdasarkan bukti empiris, (2) teori dan hukum ilmiah adalah produk sains yang memiliki hubungan tertentu dan fungsi yang berbeda, (3) perkembangan sains melibatkan imajinasi dan kreativitas manusia, (4) sains bersifat theory-laden, (5) sains dipengaruhi oleh faktor sosial dan budaya, (6) terdapat 
mitos tentang metode ilmiah dalam sains, (7) sains bersifat tentatif, (Lederman, dkk., 2002). Ketujuh aspek hakikat sains tersebut saling berkaitan dan tidak bisa berdiri sendiri (Schwartz, dkk., 2004).

Sifat empiris dari sains, artinya klaim ilmiah berasal dari dan/atau konsisten dengan observasi fenomena alam yang kemudian diinterpretasikan. Pernyataan atau klaim ilmiah apapun harus dapat dibuktikan secara empiris (Schwartz, dkk., 2004). Namun, sains bukan sekedar akumulasi bukti-bukti yang dapat diamati secara kasat mata. Semua pengamatan membutuhkan inferensi dari ilmuwan (Rahayu, 2014). Pemahaman tentang perbedaan antara observasi dan inferensi penting dimiliki sebagai dasar untuk memahami banyaknya inferensi dan istilah-istilah yang ada dalam sains (Lederman dkk., 2002). Observasi adalah pernyataan deskriptif tentang fenomena alam, yang dapat diakses langsung menggunakan indera manusia atau bantuan alat-alat teknologi, sedangkan inferensi adalah interpretasi dari hasil observasi atau dengan kata lain inferensi adalah pernyataan tentang fenomena alam yang tidak dapat diakses secara langsung oleh indera manusia (Abd-El-Khalick, dkk., 2008). Miskonsepsi yang sering terjadi adalah siswa, guru atau calon guru tidak dapat membedakan antara observasi dan inferensi. Mereka tidak bisa menjelaskan peran inferensi dalam konstruk saintifik. Menurut mereka, "seeing was knowing". Mereka mengabaikan peran inferensi dalam pembentukan konsep struktur atom, mereka menganggap bahwa ilmuwan meyakini struktur atom karena mereka dapat mengobservasi atom menggunakan mikroskop elektron yang canggih (Akerson, dkk., 2000).

Hukum ilmiah adalah pernyataan atau deskripsi tentang hubungan diantara fenomena alam yang dapat diamati, sedangkan teori ilmiah adalah penjelasan inferensi dari fenomena tersebut. Teori ilmiah dan hukum ilmiah adalah pengetahuan ilmiah yang berbeda. Teori ilmiah tidak dapat berubah menjadi hukum ilmiah, serta sebaliknya (Abd-El-Khalick, dkk., 2008). Ilmuwan tidak merumuskan teori ilmiah dengan harapan di kemudian hari teori ilmiah tersebut berubah menjadi hukum ilmiah. Teori ilmiah dapat menjelaskan hukum ilmiah (Lederman, dkk., 2002), misalnya saja teori tumbukan dapat menjelaskan hukum laju reaksi dengan baik. Miskonsepsi yang sering terjadi adalah siswa, guru atau calon guru meyakini bahwa teori ilmiah yang secara konstan teruji dan menghasilkan bukti-bukti yang mendukung akan berubah menjadi hukum ilmiah, sedangkan hukum ilmiah bersifat pasti dan tidak dapat berubah (Liang, dkk., 2009; Akerson, dkk., 2000). Mereka dengan kata lain meyakini bahwa hukum ilmiah memiliki kedudukan lebih tinggi daripada hukum ilmiah (Lederman, dkk., 2013).

Perkembangan sains tidak lepas dari keterlibatan imajinasi dan kreativitas manusia. Konsep ilmiah dalam sains tidak secara otomatis semata-mata dihasilkan dari data atau sejumlah analisis saja. Ilmuwan menggunakan imajinasi dan kreativitas selama investigasi ilmiah mereka, termasuk dalam membuat hipotesis, menemukan landasan teori, membuat prediksi, dan menemukan cara untuk menguji ide-ide mereka (National Science Teachers Association, 2000). Aspek imajinasi dan kreativitas dari sains ini, seringkali dihubungkan dengan aspek inferensi. Konsep sains seperti atom, adalah contoh hasil penggunaan imajinasi dan kreativitas dalam sains. Model atom hanyalah model teoritis, bukan merupakan duplikat dari realita yang ada (Lederman, dkk., 2013; Lederman, 1999).

Sains bersifat theory-laden. Pemahaman teoritis, keyakinan, pengetahuan yang dimiliki, pengalaman, dan ekspektasi para ilmuwan berperan dalam mempengaruhi 
kerja para ilmuwan. Semua faktor inilah yang mempengaruhi masalah apa yang akan diinvestigasi oleh ilmuwan, bagaimana mereka melakukan investigasi, apa yang akan mereka observasi, dan bagaimana mereka menginterpretasikan observasi mereka. Penting untuk diingat bahwa sains tidak pernah diawali oleh observasi netral. Observasi selalu didorong dan dipandu oleh pertanyaan atau masalah. Pertanyaan-pertanyaan atau masalah-masalah ini, pada gilirannya diperoleh dari prespektif teoritis tertentu (Lederman, dkk., 2013; Lederman, 1999; Schwartz, dkk., 2004). Misalnya, hukum perbandingan tetap menjadi dasar bagi Dalton dalam mengemukakan teori atom Dalton.

Sains dipengaruhi oleh kehidupan sosial dan budaya. Sains sebagai hasil karya manusia dipraktekkan dalam konteks budaya yang luas, dan para praktisinya (ilmuwan) adalah produk dari budaya tersebut. Sains mengikuti, mempengaruhi, dan dipengaruhi oleh budaya dimana sains diterapkan. (Lederman, dkk., 2013; Lederman, 1999), misalnya kemajuan besar dalam ilmu kimia, misalnya penemuan pupuk nitrogen dihasilkan dari keinginan untuk menghasilkan bahan peledak bagi kepentingan perang dunia II. Selain itu, sains adalah negosiasi sosial. Hal ini terkait dengan aspek komunikasi dan kritik diantara produk ilmiah yang dapat meningkatkan objektivitas pengetahuan ilmiah itu sendiri melalui penurunan efek dari faktor subjektivitas dari seorang peneliti. Proses double-blind peer-review yang digunakan pada sebuah jurnal ilmiah adalah salah satu contoh dari aspek ini (Abd-El-Khalick, dkk., 2008).

Mitos yang sering dijumpai dalam sains adalah keyakinan bahwa terdapat sebuah metode ilmiah yang berisi langkah demi langkah prosedur investigasi ilmiah yang diikuti oleh semua ilmuwan. Hal ini adalah keyakinan yang salah, ilmuwan melakukan berbagai macam metode investigasi ilmiah sesuai dengan pertanyaan ilmiah yang diajukan, seperti deduksi matematika, observasi, spekulasi, analisis, studi literatur, dan eksperimen. Pemilihan jenis metode investigasi ilmiah oleh ilmuwan juga tergantung pada pengetahuan awal mereka, kreativitas, dan paradigma penelitian yang biasanya mereka kerjakan (Kuhn, 1970). Banyak siswa, calon guru dan guru yang memiliki miskonsepsi tentang aspek ini. Mereka meyakini bahwa ilmuwan mengikuti langkah demi langkah sebuah metode ilmiah yang bersifat universal karena dapat menjamin kevalidan dan keakuratan hasil penelitian. Selain itu, mereka juga meyakini bahwa eksperimen adalah satu-satunya metode yang digunakan dalam pengembangan sains/pengetahuan ilmiah (Liang, dkk., 2009).

Kebenaran sains tidak pernah bersifat mutlak. Berbagai jenis produk sains seperti teori ilmiah dan hukum ilmiah bersifat tentatif/dapat berubah. Sains dapat mengalami perubahan jika ada bukti-bukti baru yang ditemukan karena kemajuan teknologi, melalui pengkajian ulang terhadap bukti-bukti yang ada (bukti-bukti lama) atau bahkan karena faktor sosial dan budaya atau terjadinya pergeseran program penelitian (Abd-ElKhalick, dkk., 2008; Lederman, 1999; Lederman, dkk., 2013). Perubahan yang cepat pada teori atom adalah salah satu contoh dari aspek ini. Beberapa guru, calon guru dan siswa memiliki pemahaman bahwa sains bersifat mutlak dan tidak dapat berubah (Akerson, dkk, 2000).

Pemahaman hakikat sains ditetapkan sebagai salah satu karakteristik yang diharapkan bagi seseorang yang berliterasi sains (Holbrook \& Rannikmae, 2009). Pengembangan pemahaman hakikat sains adalah salah satu tujuan pembelajaran sains yang diyakini dapat mengembangkan kemampuan literasi sains siswa (Liang, dkk., 
2009). Clough \& Olson (2012) menyatakan bahwa pembelajaran hakikat sains yang efektif membantu siswa untuk memahami konten sains. Mereka berpendapat bahwa pertama, pemahaman hakikat sains membantu siswa untuk memahami berbagai asumsi yang mendasari pengetahuan ilmiah. Kedua, pemahaman hakikat sains meningkatkan ketertarikan siswa terhadap sains dan kelas sains, sehingga hal ini akan meningkatkan motivasi untuk mempelajari konten sains. Ketiga, dengan guru membelajarkan hakikat sains secara eksplisit, konstruksi dan rekonstruksi dari ide-ide sains dibuat jelas, sehingga membantu siswa memahami bahwa beberapa ide yang mereka kemukakan mungkin juga dikemukakan oleh ilmuwan. Manfaat memasukkan hakikat sains kedalam kurikulum, diantaranya dapat meningkatkan hasil belajar tentang materi sains, minat terhadap sains, dan pengambilan keputusan terhadap masalah-masalah yang berhubungan dengan sains (Driver, dkk., 1996). Jadi pada prinsipnya, pemahaman tentang hakikat sains sangat diperlukan dalam mewujudkan masyarakat yang berliterasi sains.

\section{Peran Pembelajaran Berbasis Inkuiri Ilmiah dalam Membelajarkan Hakikat Sains}

Pembelajaran berbasis inkuiri ilmiah menekankan pada berbagai proses seperti keterampilan investigasi, mencari jawaban secara aktif dari sebuah pertanyaan tentang konsep sains tertentu, dan membangun kemampuan siswa untuk mengeksplorasi dan menilai informasi (Lederman, 2003). Pembelajaran berbasis inkuiri ilmiah merupakan kegiatan pembelajaran yang berpusat pada siswa, dimana siswa secara aktif dilibatkan dalam proses pembelajaran (Rossouw, 2009). Menurut Bencmarks for Science Literacy (AAAS, 1993), inkuiri ilmiah secara singkat mengacu pada pendekatan sistematik yang digunakan oleh ilmuwan sebagai usaha dalam menjawab pertanyaan ilmiah. Pembelajaran berbasis inkuiri ilmiah memiliki 5 aspek penyusun esensial. Pertama, siswa didorong untuk mengajukan pertanyaan yang berorientasi ilmiah. Kedua, siswa diberikan kesempatan mengembangkan prosedur dan melakukan investigasi ilmiah yang dapat menjawab pertanyaan ilmiah yang diajukan. Ketiga, siswa menganalisis data yang didapatkan dari investigasi ilmiah. Keempat, siswa membuat penjelasan berdasarkan data investigasi ilmiah yang dilakukan dan mengevaluasi penjelasan yang dibuat. Terakhir, siswa mengkomunikasikan penjelasan yang diajukan (NRC, 2000).

Anderson (2007) menyatakan bahwa kebanyakan guru memiliki sedikit pengalaman dengan inkuiri ilmiah, sehingga konsekuensinya mereka menyajikan konsep inkuiri ilmiah yang kurang tepat di kelas. Banyak guru berpendapat bahwa melakukan hands-on activities dan kegiatan eksperimen di laboratorium adalah pembelajaran berbasis inkuiri ilmiah. Padahal kenyataannya tidak semua hands-on activity adalah inkuiri ilmiah, dan tidak semua pembelajaran berbasis inkuiri ilmiah melibatkan hands-on activity. Melakukan kegiatan secara fisik bukanlah unsur penting dalam pembelajaran berbasis inkuiri ilmiah. Hal yang paling penting adalah siswa mampu mengajukan pertanyaan, mengumpulkan data, membuat penjelasan berdasarkan bukti, dan mengkomunikasikan penjelasan berdasarkan data yang dikumpulkan (Llewellyn, 2005).

Penting untuk menekankan bahwa kita tidak boleh mengasumsikan bahwa siswa akan memahami hakikat sains sebagai hasil dari melakukan kegiatan berbasis inkuiri ilmiah. Kegiatan berbasis inkuiri ilmiah hanyalah awal, siswa perlu untuk merefleksikan 
apa yang mereka lakukan. Mereka perlu untuk dilibatkan dalam diskusi mengapa investigasi ilmiah didesain dengan cara tertentu. Siswa perlu untuk mendiskusikan asumsi-asumsi yang tidak dapat dipisahkan dari berbagai investigasi ilmiah dan implikasi asumsi-asumsi ini untuk hasil investigasi. Lebih jauh lagi, siswa perlu untuk mendiskusikan fakta bahwa sains dikerjakan oleh manusia, dan hal ini memiliki implikasi untuk pengetahuan yang dihasilkan. Hakikat sains harus dipikirkan sebagai hasil belajar kognitif. Jika siswa diharapkan dapat mengembangkan pemahaman hakikat sains, maka tujuan ini harus direncanakan, diajarkan secara eksplisit, dan dinilai (Lederman, dkk., 2013).

Pembelajaran berbasis inkuiri ilmiah merupakan salah satu pendekatan yang dapat digunakan untuk meningkatkan pemahaman hakikat sains siswa (Lederman, 2003). Banyak hasil penelitian menyatakan bahwa pembelajaran berbasis inkuiri ilmiah adalah cara yang efektif untuk mengembangkan pemahaman hakikat sains siswa. Pembelajaran kimia yang melibatkan pengalaman berinkuiri ilmiah juga dapat mengembangkan pemahaman hakikat sains siswa dengan lebih baik. Hasil penelitian Yuliastini (2017) menyatakan bahwa terjadi peningkatkan pemahaman hakikat sains siswa SMK yang dibelajarkan menggunakn inkuiri ilmiah pada materi larutan elektrolit dan reaksi redoks. Hasil penelitian Ratnawati (2016) juga menunjukkan bahwa pemahaman hakikat sains siswa SMA mengalami peningkatan setelah dibelajarkan menggunakan pembelajaran berbasis inkuiri ilmiah pada materi larutan penyangga dan hidrolisis garam, sedangkan hasil penelitian yang dilakukan oleh Nurhayati, (2016) juga menunjukkan hasil yang serupa pada materi kelarutan dan hasil kali kelarutan.

Pemahaman inkuiri ilmiah adalah syarat awal untuk mengimplementasikan pembelajaran berbasis inkuiri ilmiah di kelas (Leon, 2015; Wenning, 2005). Inkuiri ilmiah dipandang sebagai karakteristik yang diinginkan dalam proses pembelajaran sains, oleh karena itu guru sains perlu memahami dengan baik inkuiri ilmiah dan metode-metode inkuiri ilmiah (NRC, 2000). Telah diketahui bahwa pemahaman hakikat sains siswa dipengaruhi oleh pengalaman mereka dalam melakukan kegiatan inkuiri ilmiah yang dibimbing oleh guru sains di sekolah. Pemahaman hakikat sains dan inkuiri ilmiah guru sains jelas diperlukan untuk membantu siswa memahami hakikat sains yang pada akhirnya meningkatkan literasi sains siswa. Bukan hanya guru, tetapi calon guru termasuk calon guru kimia juga diharapkan memiliki pemahaman hakikat sains dan inkuiri ilmiah yang baik, karena kimia adalah bagian dari sains. Hal ini diperlukan agar nanti pada saatnya melaksanakan tugas sebagai guru kimia mampu membelajarkan hakikat sains dengan baik melalui pembelajaran berbasis inkuiri ilmiah.

\section{KESIMPULAN}

Pemahaman hakikat sains merupakan komponen penting dalam literasi sains. Pemahaman hakikat sains siswa sangat bergantung pada pemahaman hakikat sains guru. Guru perlu memiliki pemahaman hakikat sains yang baik dan cara membelajarkannya salah satunya melalui pembelajaran berbasis inkuiri ilmiah. Pemahaman hakikat sains dan inkuiri ilmiah yang baik penting dimiliki oleh guru dan calon guru, termasuk calon guru kimia. Hal ini diperlukan agar nanti pada saatnya melaksanakan tugas sebagai guru kimia mampu membelajarkan hakikat sains dengan baik melalui pembelajaran berbasis inkuiri ilmiah. 


\section{DAFTAR RUJUKAN}

Abd-El-Khalick, F., Waters, M., \& Le, A. 2008. Representations of Nature of Science in High School Chemistry Textbooks over the Past Four Decades. Journal of Research in Science Teaching, 45(7): 835-855.

American Association for the Advancement of Science (AAAS). 1993. Benchmarks for science literacy. NY: Oxford University Press.

Anderson, R.D. 2007. Inquiry as an Organizing Theme for Science Curricula. Dalam S.K. Abell \& N.G. Lederman (Eds.), Handbook of Research on Science Education (hlm. 807-830). New York: Routledge.

Akerson, V.L., Abd-El-Khalick, F., \& Lederman, N.G. 2000. Influence of a Reflective Explicit Activity-Based Approach on Elementary Teachers' Conceptions of Nature of Science. Journal of Research in Science Teaching, 37(4): 295-317.

Allchin, D. 2011. Evaluating Knowledge of The Nature of (Whole) Science. Science Education, 95, 918-942.

Bell, R.L. 2007. Teaching the Nature of Science through Process Skills: Activities for Grades 3-8. New York: Allyn \& Bacon/Longman.

Crawford, B. 2012. Moving The Essence of Inquiry Into The Classroom: Engaging Teachers and Students in Authentic Research. Dalam K.C.D. Tan \& M. Kim (Eds.), Issues and Challenges in Science Education Research: Moving Forward (hlm. 25-42). Dordrecht: Springer.

Clough, M.P. and Olson, J.K. 2012. Impact of a Nature of Science and Science Education Course on Teachers' Nature of Science Classroom Practices. Dalam Myint Swe Khine (Ed.), Advance in Nature of Science Research: Concept and Methodologies. Springer Dordrecht Heidelberg London New York.

Driver, R., Leach, J., Miller, A., \& Scott, P. 1996. Young people images of science. Pennsylvania: Open University Press.

Holbrook, J, \& Rannikmae, M. 2009. The meaning of scientific literacy. International Journal of Environmental \& Science Education, 4(3): 275-288

Hurd, P.D. 1998. Scientific Literacy: New Minds for a Changing World, Science Education, 82: 407-416.

Khishfe, R. 2012. Nature of Science and Decision-Making. International Journal of Science Education, 34 (1): 67-100.

Kuhn, T. S. 1970. The Structure of Scientific Revolutions. Chicago: University of Chicago Press.

Lederman, N.G. 2003. Letters: Inquiring about Inquiry. Science and Children, 40 (8): 9.

Lederman, N.G. 1992. Students' and Teachers' Conceptions of the Nature of Science: A Review of the Research. Journal of Research in Science Teaching, 29 (4): 331-359.

Lederman, N.G. 1999. The State of Science Education: Subject Matter Without Context. Electronic Joumal of Science Education. (Online), Volume 3 Nomor 2, (http:/ / ejse.southwestern.edu/article/view/7602/5369 diakses 28 Januari 2017).

Lederman, N.G., Abd-El-Khalick, F., Bell, R.L. \& Schwartz, R.S. 2002. Views of Nature of Science Questionnaire: Toward Valid and Meaningful Assessment of Learners' Conceptions of Nature of Science. Journal of Research in Science Teaching, 39, 497-521.

Lederman, N.G., Lederman, J.S., \& Antink, A. 2013. Nature of Science and Scientific Inquiry as Contexts for the Learning of Science and Achievement of Scientific Literacy. International Journal of Education in Mathematics, Science and Technology, 1 (3): 138-147.

Leon, M.R. 2015. Science Teachers Understanding of Inquiry-Based Science Teaching (IBST): Case of Rwandan Lower Secondary School Science Teachers. Rwandan Journal of Education, 3 (1): 77-90.

Liang, L.L., Chen, S., Chen, X., Kaya, O.N., Adams, A.D., Macklin, M., \& Ebenezer, J. 2009. Preservice Teachers' Views about Nature of Scientific Knowledge Development: an International Collaborative Study. International Journal of Science and Mathematics Education, 7:987-1012 
Llewellyn, D. 2005. Teaching High School Science Through Inquiry. California: Corwin Press.

National Research Council. 2000. Inquiry and the National Science Education Standards. Washington, DC: National Academy Press.

National Science Teachers Association. 2000. NSTA Position Statement: The Nature of Science. Arlington, VA: National Science Teachers Association Press.

Norris S.P., \& Phillips, L.M. 2003. How literacy in its fundamental sense is central to scientific literacy. Science Education, 87, 224-240.

Nurhayati, H. M.2016. Pengaruh Pembelajaran Kimia dengan LC-5E Berkonteks SSI Terhadap Pemahaman Hakikat Sains, Keterampilan Berpikir Kritis, dan Penguasaan Konsep Kelarutan Siswa SMA. Tesis tidak diterbitkan. Malang: Pascasarjana Universitas Negeri Malang.

OECD-PISA. 2006. Science Competencies for Tommorow's Word. Volume 1: Analysis. USA: OECDPISA. Tersedia www.pisa.oecd.org.

Rahayu, S. 2014. Menuju Masyarakat Berliterasi Sains: Harapan dan Tantangan Kurikulum 2013. Makalah disajikan dalam Seminar Nasional Kimia dan Pembelajarannya 2014. Universitas Negeri Malang, Malang, 6 September.

Ratnawati, E. 2016. Pengaruh Learning Cycle-5E Berkonteks SSI Terhadap Pemahaman Hakikat Sains, Keterampilan Berpikir Kritis, dan Penguasaan Konsep Larutan Penyangga dan Hidrolisis Garam Siswa SMA. Tesis tidak diterbitkan. Malang: Pascasarjana Universitas Negeri Malang.

Rossouw, D. 2009. Educators As Action Researchers: Some Key Considerations. South African Journal of Education, 29: 1-16.

Schwartz, R.S., Lederman, N.G., \& Crawford, B.A. 2004. Developing Views of Nature of Science in an Authentic Context: An Explicit Approach to Bridging the Gap Between Nature of Acience and Scientific Inquiry. Science Teacher Education. 88 (4): 610-645.

Wenning, C.J. 2005. Implementing Inquiry-based Instruction in the Science Classroom: A New Model for Solving the Improvement-of-Practice Problem. JPTEO, 2 (4): 9-15.

Yuliastini, I.B. 2017. Efektifitas Pogil Berkonteks Ssi Terhadap Pemahaman Hakikat Sains, Motivasi Belajar Dan Pemahaman Konsep Siswa Smk Pada Materi Larutan Elektrolit Dan Reaksi Redoks. Tesis tidak diterbitkan. Malang: Pascasarjana Universitas Negeri Malang. 